\title{
Can central venous access device care bundles and regular feedback reduce central line-associated complications in pediatric patients?
}

\author{
Chanapai Chaiyakulsil, MD, Onsuthi Pharadornuwat, MD \\ Division of Pediatric Critical Care, Department of Pediatrics, Faculty of Medicine, Thammasat University, Prathumthani, Thailand
}

Background: The use of indwelling central venous access devices (CVADs) in children can result in complications such as infection, occlusion, and dislodgement.

Purpose: To evaluate whether reinforcing CVAD care bundles by using a regular direct feedback system could reduce such complications in children.

Methods: The intervention in this retrospective interrupted time-series study was initiated in January 2019. The study was divided into the preintervention (October-December 2018), 3month postintervention (January-March 2019), and 6-month postintervention (April-June 2019) phases. Risk difference and Poisson regression analyses were used to illustrate the effectiveness of the intervention.

Results: The hospital-wide central line-related bloodstream infection rate decreased from 10.0/1,000 catheter-days to 4.5/ 1,000 catheter-days at 3 -month postintervention $(P=0.39)$ and to $1.4 / 1,000$ catheter-days at 6 -month postintervention $(P=$ 0.047). The central line occlusion rate significantly decreased from $30 \%$ to $12.8 \%(P=0.04)$ and $8.3 \%(P=0.002)$ at 3 and 6 months, respectively. Approximately 7\% of CVADs became dislodged during the preintervention phase versus $8.5 \%(P=$ $0.364)$ and $3.3 \%(P=0.378)$ at 3 and 6 months, respectively.

Conclusion: Reinforcing CVAD care bundles with direct feedback could significantly decrease CVAD-associated complications in terms of infection at 6-month postintervention, and occlusion at 3- and 6-month postintervention. Thus, reinforcement and regular direct feedback might improve care quality in children with CVADs.

Key words: Patient care bundles, Central line infection, Occlusion, Pediatrics, Prevention

\section{Key message}

Question: Can central line bundles and feedback reduce central line-associated complications in pediatric patients?

Finding: The central line-related bloodstream infection rate decreased from 10.0 catheter-days to $1.4 / 1,000$ catheter-days at 6-month postintervention. The central line occlusion rate was also decreased.

Meaning: Reinforcing central line care bundles with direct feedback can significantly decrease central line-associated complications in pediatric patients.

\section{Introduction}

Central venous access devices (CVADs) play an integral role in the medical management of many pediatric conditions. ${ }^{1,2)}$ It provides an efficient delivery of antibiotics, chemotherapy, parenteral nutrition, and other lifesaving medications which require large-caliber vessels to avoid vascular irritation and drug extravasation. Furthermore, central venous access also provides an access route for lifesaving interventions such as hemodialysis and plasmapheresis. ${ }^{3,4)}$ Despite its usefulness, indwelling CVADs can result in several possible complications such as central lineassociated bloodstream infection (CLABSI), central line-related bloodstream infection (CRBSI), central line occlusion, deep vein thrombosis, or line dislodgement. ${ }^{1,2,5)}$ These complications lead to longer hospital stays and higher medical costs. $1,2,5,6)$ Approximately 250,000 CLABSIs occurred in United States hospitals each year with a mortality rate as high as $25 \% .^{7-9)}$ The estimated cost of treatment ranges from $\$ 5,821$ to $\$ 60,536$ per event. ${ }^{10,11)}$ From the current systematic review in pediatrics by Ullman et al., ${ }^{2}$ it revealed that about $25 \%$ of CVADs failed before completion of treatment. CLABSI were found to occur in 10.3\% of all catheters with an incidence rate of 1.4-1.86 episodes $/ 1,000$ catheter-days. A total of $7.4 \%$ and $4.7 \%$ of all catheters were found to have occlusion and dislodgement, respectively. As of present, there were only 2 single-center studies reporting central line complications in pediatrics in Thailand, which demonstrated an infection rate of 2.6-7.5 episodes/1,000 catheter-days. ${ }^{12,13)}$ These figures demonstrated that Thailand had higher infection rates when compared to that of the current systematic review.

\footnotetext{
Corresponding author: Chanapai Chaiyakulsil, MD. Division of Pediatric Critical Care, Department of Pediatrics, Faculty of Medicine, Thammasat University. 95 Phahol Yothin Road, Klong-Neung, Klong-Luang, Prathumthani 12120, Thailand

凶Email: chanapai.chai@hotmail.com, https://orcid.org/0000-0003-4677-4223

Received: 27 January, 2020, Revised: 9 June, 2020, Accepted: 23 June, 2020

This is an open-access article distributed under the terms of the Creative Commons Attribution Non-Commercial License (http://creativecommons.org/licenses/bync/4.0/) which permits unrestricted non-commercial use, distribution, and reproduction in any medium, provided the original work is properly cited.

Copyright (c) 2021 by The Korean Pediatric Society
} 


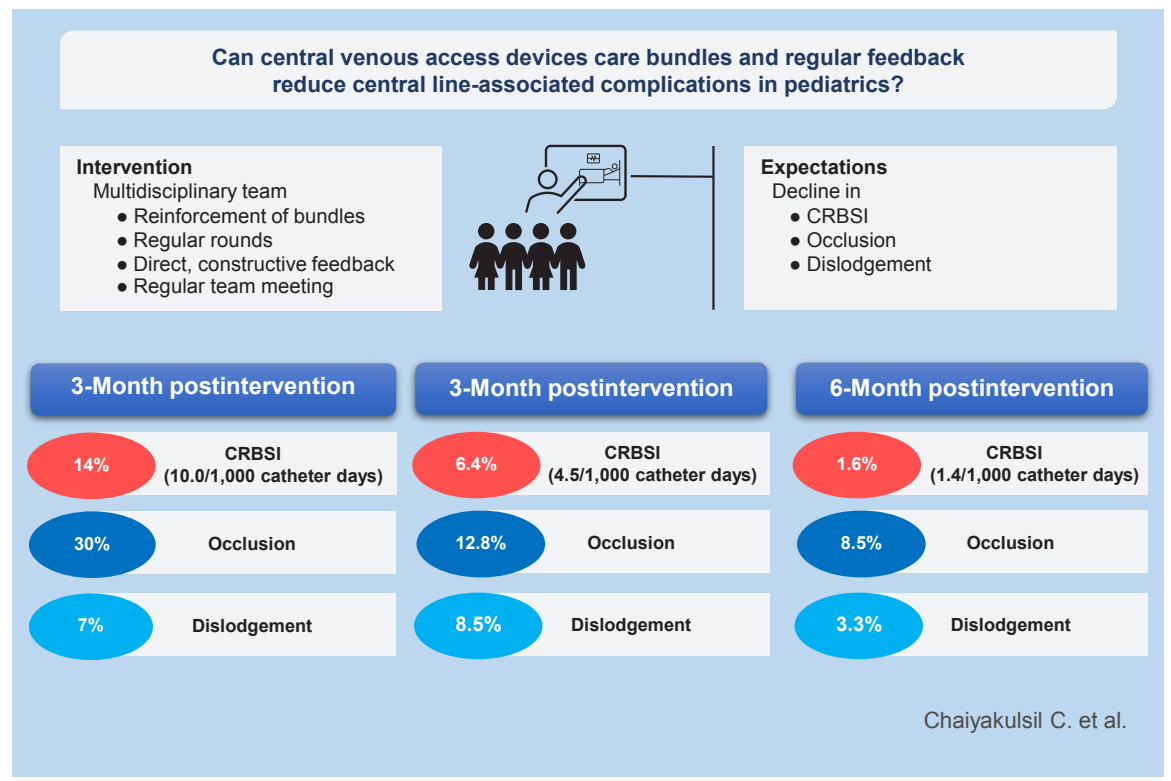

Graphic abstract

Many studies were previously done in the utilization of CVADs care bundles in order to reduce CVADs associated infection which resulted in favorable outcomes. ${ }^{1,7,9,13-17)}$

Nevertheless, most studies were conducted in developed countries such as the United States, Australia, Europe, or developed Asian countries and mostly aimed for reduction of infection rather than other complications such as occlusion or line dislodgement. Furthermore, most studies concentrated on the implementation of bundles rather than reinforcing the bundles with regular review and feedback. By using reinforcement and a direct feedback system, it may enhance the compliance of the bundles and provides early intervention for any altercation that may occur during CVADs care. Moreover, many of the studies focused on specific groups of patients such as oncology patients and critically ill children.

Thus, the objectives of this study were to determine the incidence of CVADs associated complications in terms of infection, central line occlusion, and dislodgement and to determine whether reinforcement of care bundles and direct feedback could reduce such complications. This study included hospitalwide children receiving CVADs and not restricted to only critically ill children and oncology patients.

\section{Methods}

\section{Study design}

This study was conducted in a retrospective, interrupted time-series fashion. The Ethics Committee of Thammasat University Hospital approved this research (IRB number: MTUEC-PE 0-128/62) and informed consent was waived due to the retrospective nature of the study.

\section{Participants}

All children from neonates to 15 years old who received CVADs insertion from October 2018 to June 2019 at Thammasat University Hospital (TUH), Thailand except neonates who received peripherally inserted central catheter (PICC) insertion were included for analysis. Neonatal PICC was specifically cared for by neonatologists using different bundles. TUH is a large tertiary, university hospital which received at least 400 admissions in all pediatric wards per month. Approximately 15-20 CVADs were inserted per month.

\section{Intervention}

As a standard in our center, all CVADs access were performed by pediatric intensivists, interventional radiologist, or anesthesiologists who specialize in pediatric vascular access using ultrasound-guided venipuncture with modified Seldinger technique under maximal barriers. The choice of CVADs type (nontunneled catheter, PICC, or tunneled catheter [Broviac, Bard Peripheral Vascular Inc., Arizona, USA]) to be implanted were chosen at the time of consultation depending on the indication of CVADs and expected duration of utilization. Patients requiring intravenous access for more than 2 weeks would be chosen to implant PICC rather than nontunneled catheter. Internal jugular vein was a preferable site of insertion compared to the femoral vein. In Thailand, sutureless securement devices were not readily available, thus nylon 3-0 suture was used for securement.

CVADs care bundles were first implemented at TUH in 2014. As a quality improvement project of the hospital, a revised version of CVADs care bundles and a new system of regular direct feedback on CVADs care were implemented in January 2019. Revised CVADs care bundles were described in Table 1 using the HOPERD acronym.

The bundles' compliance and direct feedback were reinforced 


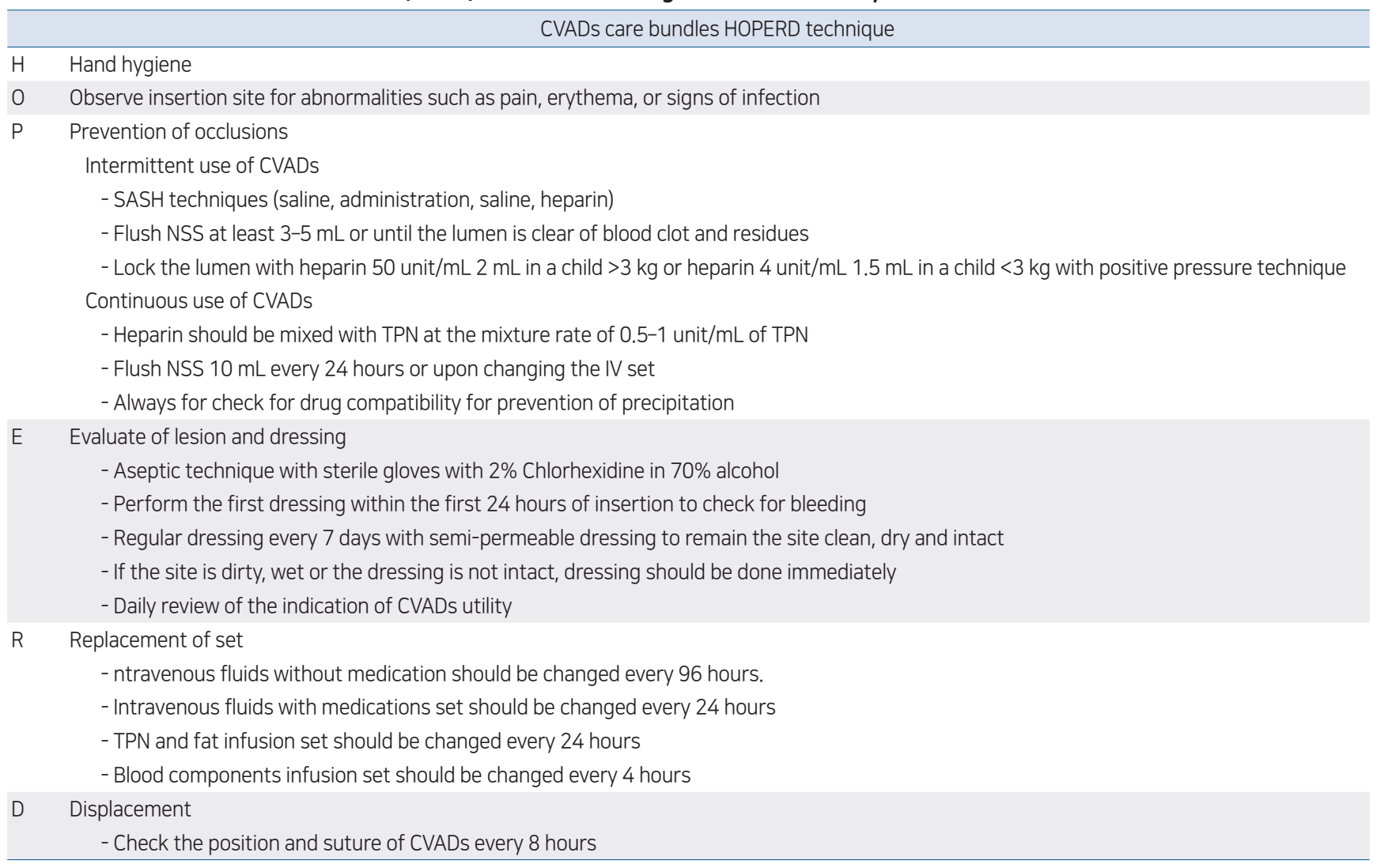

by a multidisciplinary vascular access team. The team encompassed of pediatric nurses who specialized in pediatric vascular access care, general pediatric nurses, and pediatric intensivists. Each team member underwent standardized training with bundles protocols in terms of tubing changes, dressing changes, and line access for blood draws and medications. Multidisciplinary team rounds were done on a weekly basis on every CVADs in the hospital. The team provided direct, constructive feedback for the improvement of CVADs care to general nurses and residents who were responsible for the CVADs care on a daily basis. During the rounds, the performance of the CVADs care along with bundles compliance was assessed by the team along with the necessity of CVADs access. Discussion was made upon the expected duration of CVADs utilization in each case. If the period of utilization was expected to be more than 2 weeks, the team would suggest a possible transition from a nontunneled catheter to a more permanent catheter. The suggestion of line removal was also given by the team if the indication for CVADs access was not fulfilled. After rounds, general nurses, residents, and the vascular access team meet for debriefing. During the debriefing, verbal feedback on the flushing technique and wound dressing were given. Tubing changes techniques, line access techniques for medications, and blood draw were also reviewed if mistakes were detected during rounds. Strict hand hygiene practice was encouraged during rounds and debriefing. The team also provided 24-hour availability for consultation.

\section{Terminology of complications}

1) Infection

(1) Central line-associated bloodstream infection (CLABSI) ${ }^{18)}$

a recovery of a pathogen from blood culture in patients who had indwelling CVADs at the time of infection or within 48 hours before the development of infection. Only single positive blood culture was needed for organisms not commonly present in the skin, but 2 or more positive blood cultures were needed for common skin organisms. This should not be an infection related to another site.

(2) Central line-related bloodstream infections (CRBSI) ${ }^{19)}$

Isolation of the same pathogen from blood culture drawn through the central line and from a peripheral vein

(1) With bacterial colony count at least threefold higher in the sample from the central line as compared to that obtained from the peripheral vein.

(2) Shorter time to positive culture in central line compared to that of the peripheral line ( $>2$ hours earlier).

This study would use CRBSI incidence rather than CLABSI. If the patient had a positive culture from only either central line or peripheral vein, the diagnosis of contamination and septicemia would be given respectively instead of CRBSI.

2) Occlusion ${ }^{20)}$

(1) Partial occlusion: where blood could not be aspirated but infusion was still possible 
(2) Complete occlusion: inability to both aspirate and infuse blood or medications within that catheter.

As of this study, only complete occlusion of any lumen in a catheter would be considered.

3) Dislodgement

(1) Unintentional removal of CVADs by either a patient or a provider.

(2) This can be detected by visualizing a tip of the catheter outside the patient's body

\section{Data collection}

Data from October to December 2018 was served as a preimplementation period and data from January to June 2019 was considered as a postimplementation phase. The data in the postimplementation period was analyzed every 3 months for 2 time periods (January to March 2019 and April to June 2019) for evaluation of possible improvement. All demographic data and complications in terms of infection, occlusion, and dislodgement were recorded.

\section{Statistical analyses}

Demographic data were illustrated using descriptive statistics. CRBSI rate was described using an event per 1,000 catheterdays. Complete occlusion, as well as dislodgement rate, were demonstrated using percent per total catheter used. Risk regression analyses, Poisson regression analysis, incidence rate ratios (IRR), and 95\% confidence interval (95\% CI) were used in the assessment of the effectiveness of the intervention. All statistical analyses were performed using IBM SPSS Statistics ver. 24.0 (IBM Co., Armonk, NY, USA) and Stata ver. 15 (StataCorp LLC, College Station, TX, USA).

\section{Results}

\section{Study population}

A total of 152 catheters were utilized throughout the study period. The mean age of the whole cohort was 2.8 years old with the average time for catheter use of 13.4 days (range, 1-134 days). Children with underlying congenital heart diseases such as ventricular septal defect, double outlet right ventricle, and Tetralogy of Fallot contributes to about one-third of the catheters utilized in this cohort. Twenty-seven catheters (17\%) were utilized in children with congenital heart diseases who required cardiac surgery. These were categorized under postoperative in Table 2. Inotropy was the most common indication for CVADs access. Most commonly utilized CVADs were nontunneled catheter (>90\%). About $80 \%$ of patients were admitted in the intensive care unit during CVADs access. The demographic data for each period were summarized in Table 2. Half of the CVADs insertions were performed under emergency settings where patients required prompt intravenous access for resuscitation and inotropic support (Table 3).

\section{Infection}

After the intervention, CRBSI decreased from 10.0/1,000 catheter-days to $4.5 / 1,000$ catheter-days during the first 3 months (IRR, 0.49; 95\% CI, 0.10-2.44; $P=0.39$ ). During the 4th to 6 th months of the study, the rate significantly de-escalated to $1.4 / 1,000$ catheter-days (IRR, 0.08 ; $95 \% \mathrm{CI}, 0.01-0.965$; $P<$ 0.05 ) (Table 3). CRBSI pathogens consist of both gram-negative pathogens such as Acinetobacter species, Enterobacter, and Klebsiella pneumoniae as well as gram-positive pathogens such as Enterococcus and Staphylococcus. Numbers of emergency CVADs access were not significantly different among periods (Table 3). Emergency CVADs and intensive care unit admission were not associated with an increasing rate of CRBSI $(P>0.05)$.

\section{Occlusion}

CVADS complete occlusion rates significantly declined from $30 \%$ during preintervention period to $12.8 \%$ (percent reduction, $17.2 \%$; 95\% CI, 7.9\%-34.1\%; $P=0.04$ ) and $8.3 \%$ (percent reduction, $21.7 \%$; 95\% CI 7.9-36.3; $P=0.002)$ at 3 - and 6-month postintervention, respectively (Table 3 ). The hematologic characteristics of the patients among each period were not statistically different.

\section{Dislodgement}

The dislodgement rates were not significantly altered by the intervention. During the preintervention phase, approximately $7 \%$ of CVADs was dislodged compared with $8.5 \%$ at 3 - month postintervention (percent increment, 1.5\%; 95\% CI, $-6.7 \%$ to $18.3 \% ; P=0.364$ ) and $3.3 \%$ at 6 months (percent reduction, $3.7 \%$; $95 \%$ CI, $-12.1 \%$ to $4.6 \% ; P=0.378$ ) (Table 3 )

\section{Discussion}

Our study showed that the rate of CVADs associated complications, especially CRBSI and occlusion, declined after the reinforcement of bundles with regular feedback. The longest duration without CRBSI in our cohort was 106 days. According to the Center for Disease Control and Prevention (CDC), CLABSI and CRBSI were used interchangeably in the literature. CRBSI is a clinically adopted definition used for diagnosis and treatment of patients which requires specific laboratory testing to identify the catheter as the source of bloodstream infection. CLABSI is a term used by CDC to serve as a simpler definition for surveillance purposes. CLABSI is defined as a laboratory-confirmed bloodstream infection with a recovery of the pathogens in the bloodstream of the patients who had central line at the time of infection or within 48 hours before the development of infection. Since patients who had indwelling catheters within 48 hours could have bloodstream infections from other causes rather than central line-associated infection alone, thus overestimating the true incidence of CVADs infection. Therefore, in order to define infection specific to that of CVADs, this study used CRBSI incidence rather than CLABSI. ${ }^{18,21)}$ 
Table 2. Patients' demographic data

\begin{tabular}{|c|c|c|c|}
\hline Variable & $\begin{array}{l}\text { Preinter- } \\
\text { vention } \\
\text { period } \\
(\mathrm{N}=43)\end{array}$ & $\begin{array}{l}\text { 3-Month } \\
\text { postinter- } \\
\text { vention } \\
(\mathrm{N}=47)\end{array}$ & $\begin{array}{c}\text { 6-Month } \\
\text { postinter- } \\
\text { vention } \\
(\mathrm{N}=62)\end{array}$ \\
\hline Age (yr) & $3.19 \pm 10.15$ & $3.06 \pm 8.06$ & $2.53 \pm 7.72$ \\
\hline Male sex & $18(41.9)$ & $24(51.1)$ & $34(54.8)$ \\
\hline \multicolumn{4}{|l|}{ Underlying diseases } \\
\hline Cardiology & $12(27.9)$ & $18(38.3)$ & $21(33.9)$ \\
\hline Pulmonology & $7(16.3)$ & $1(2.1)$ & - \\
\hline Neurology & - & $4(8.5)$ & $7(11.3)$ \\
\hline Nephrology & $6(14.0)$ & - & $3(4.8)$ \\
\hline Preterm & $5(11.6)$ & $2(4.3)$ & $4(6.5)$ \\
\hline Allergy & $3(7)$ & $2(4.3)$ & - \\
\hline Gastrointestinal & $2(4.6)$ & $3(6.4)$ & $4(6.5)$ \\
\hline Hematology and oncology & $1(2.3)$ & $5(10.6)$ & $3(4.8)$ \\
\hline Genetic & $1(2.3)$ & $5(10.6)$ & $10(16.1)$ \\
\hline None & $6(14.0)$ & $7(14.9)$ & $10(16.1)$ \\
\hline \multicolumn{4}{|l|}{ Admission diagnosis } \\
\hline Cardiology & $13(30.2)$ & $17(36.2)$ & $24(38.7)$ \\
\hline Postoperative & 5 & 11 & 11 \\
\hline Congestive heart failure & 3 & 5 & 5 \\
\hline Pulmonary hypertensive crisis & 1 & & \\
\hline Hypoxic spell & 1 & & \\
\hline $\begin{array}{l}\text { Total anomalous pulmonary } \\
\text { venous return with obstruction }\end{array}$ & 1 & & \\
\hline $\begin{array}{l}\text { Transposition of great arteries } \\
\text { with cardiac arrest }\end{array}$ & & 1 & \\
\hline Post cardiac arrest & & & 4 \\
\hline Hypoxic spell & & & 1 \\
\hline Cardiogenic shock & & & 2 \\
\hline Shunt obstruction & & & 1 \\
\hline Pulmonology & $9(20.9)$ & $8(17.0)$ & $6(9.7)$ \\
\hline Pneumonia & 3 & 2 & 2 \\
\hline Invasive pulmonary aspergillosis & 3 & & \\
\hline Laryngomalacia & & & 2 \\
\hline Pulmonary mass & 1 & & \\
\hline Tracheitis & 1 & & 1 \\
\hline $\begin{array}{l}\text { Acute respiratory distress } \\
\text { syndrome }\end{array}$ & 1 & 4 & \\
\hline Upper airway obstruction & & 1 & \\
\hline $\begin{array}{l}\text { Bronchopulmonary dysplasia with } \\
\text { spell }\end{array}$ & & 1 & \\
\hline Bronchopulmonary dysplasia & & & 1 \\
\hline Gastrointestinal & 8 (18.6) & $4(8.5)$ & $9(14.5)$ \\
\hline Corrosive ingestion & 1 & & \\
\hline Gastroschisis & 2 & & 1 \\
\hline Hemoperitoneum & 1 & & \\
\hline Hypertrophic pyloric stenosis & 1 & & \\
\hline Necrotizing enterocolitis & 2 & & 3 \\
\hline Severe diarrhea with shock & 1 & & \\
\hline Gastric volvulus & & 2 & \\
\hline Gastroesophageal reflux disease & & 1 & 1 \\
\hline Upper gastrointestinal hemorrhage & & 1 & 1 \\
\hline Gastric outlet obstruction & & & 1 \\
\hline Blunt abdominal trauma & & & 1 \\
\hline Midgut volvulus & & & 1 \\
\hline
\end{tabular}

Table 2. Patients' demographic data (Continued)

\begin{tabular}{|c|c|c|c|}
\hline Variable & $\begin{array}{l}\text { Preinter- } \\
\text { vention } \\
\text { period } \\
(\mathrm{N}=43)\end{array}$ & $\begin{array}{l}\text { 3-Month } \\
\text { postinter- } \\
\text { vention } \\
(\mathrm{N}=47)\end{array}$ & $\begin{array}{c}\text { 6-Month } \\
\text { postinter- } \\
\text { vention } \\
(\mathrm{N}=62)\end{array}$ \\
\hline Infectious disease & $6(14.0)$ & $6(12.8)$ & $7(11.3)$ \\
\hline Septic shock & 6 & 6 & 6 \\
\hline Dengue shock syndrome & & & 1 \\
\hline Neurology & $3(7.0)$ & $3(6.4)$ & $5(8.1)$ \\
\hline Encephalitis & 1 & 2 & \\
\hline Intracerebral hemorrhage & 1 & 1 & \\
\hline Meningitis & 1 & & \\
\hline Hypoxic ischemic encephalopathy & & & 2 \\
\hline Pineal gland tumor & & & 1 \\
\hline Status epilepticus & & & 1 \\
\hline Meningomyelocele & & & 1 \\
\hline Nephrology & $3(7.0)$ & $4(8.5)$ & $3(4.8)$ \\
\hline End-stage renal disease & 3 & & \\
\hline Hypertensive urgency & & 1 & \\
\hline Nephritonephrotic syndrome & & 1 & \\
\hline $\begin{array}{l}\text { Rapidly progressive } \\
\text { glomerulonephritis }\end{array}$ & & 1 & \\
\hline Urinary tract infection & & 1 & 1 \\
\hline Hypernatremia & & & 1 \\
\hline Pseudohypoaldosteronism & & & 1 \\
\hline Allergy/rheumatology & $1(2.3)$ & $1(2.1)$ & - \\
\hline Eosinophilic esophagitis & 1 & & \\
\hline Polyarteritis nodosa & & 1 & \\
\hline Hematology and oncology & - & $4(8.5)$ & $5(8.1)$ \\
\hline Factor 7 deficiency & & 1 & 1 \\
\hline Lymphoma & & 1 & \\
\hline Germ cell tumor & & 2 & \\
\hline Gluteal mass & & & 1 \\
\hline Osteosarcoma & & & 1 \\
\hline Teratoma & & & 1 \\
\hline Acute lymphoblastic lymphoma & & & 1 \\
\hline Genetic & - & - & $3(4.8)$ \\
\hline Glycogen storage disease & & & 1 \\
\hline Methylmalonic acidemia & & & 2 \\
\hline \multicolumn{4}{|l|}{ Indications } \\
\hline Lack of peripheral access & $16(37.2)$ & $15(31.9)$ & $19(30.7)$ \\
\hline Inotropy & $17(39.5)$ & $25(53.3)$ & $34(54.8)$ \\
\hline Extracorporeal & $3(7.0)$ & $1(2.1)$ & - \\
\hline Prolonged antibiotics & $7(16.3)$ & $5(10.6)$ & $7(11.3)$ \\
\hline Chemotherapy & - & $1(2.1)$ & $2(3.2)$ \\
\hline \multicolumn{4}{|l|}{ Type of CVAD } \\
\hline Nontunneled catheter & $39(90.7)$ & $44(96.7)$ & $60(96.8)$ \\
\hline PICC & $1(2.3)$ & $1(2.1)$ & $1(1.6)$ \\
\hline Dialysis catheter & $3(7.0)$ & $1(2.1)$ & - \\
\hline Tunneled catheter & - & $1(2.1)$ & $1(1.6)$ \\
\hline \multicolumn{4}{|l|}{ Site of CVAD insertion } \\
\hline Pediatric intensive care unit & $27(62.8)$ & $31(65.9)$ & 38 (61.3) \\
\hline Neonatal intensive care unit & $8(18.6)$ & $3(6.4)$ & $9(14.5)$ \\
\hline General ward & $4(9.3)$ & $3(6.4)$ & $2(3.2)$ \\
\hline Operating room & $4(9.3)$ & $10(21.3)$ & $13(21.0)$ \\
\hline
\end{tabular}

Values are presented as mean \pm standard deviation or number (\%).

CVAD, central venous access device; PICC, peripherally inserted central catheter. 
Table 3. Total catheter days and incidence of central venous access device-associated complications by study period

\begin{tabular}{lccc}
\hline Variable & Preintervention period $(\mathrm{N}=43)$ & 3-Month postintervention $(\mathrm{N}=47)$ & 6-Month postintervention $(\mathrm{N}=62)$ \\
\hline Mean catheter days (range) & $13.9(1-80)$ & $14.1(1-134)$ & $12.3(1-75)$ \\
Emergency CVAD & $24(55.8)$ & $22(46.8)$ & $34(54.8)$ \\
CRBSI, $\mathrm{n}(\%)$ & $6(14.0)$ & $3(6.4)$ & $1(1.6)^{*}$ \\
CRBSI rate (per 1,000 catheter-days) & 10.0 & 4.5 & $1.4^{*}$ \\
CRBSI pathogens & & 1 & 1 \\
Acinetobacter Baumanii & 1 & - & - \\
Acinetobacter petii & 1 & 1 & - \\
Bacillus cereus & 1 & - & - \\
Enterobacter cloacae & - & - & - \\
Enterococcus faecalis & 1 & 1 & - \\
Klebsiella pneumoniae & 2 & $6(12.8)^{*}$ & - \\
Staphylococcus capitis & - & $4(8.5)$ & $5(8.5)^{*}$ \\
Total occlusion, $n$ (\%) & $13(30)$ & $3(7)$ & $2(3.3)$ \\
Dislodgement, $n$ (\%) &
\end{tabular}

CVAD, central venous access device; CRBSI, catheter-related bloodstream infections.

$* P<0.05$ compared to baseline.

Albeit no statistically significant reduction of CRBSI at 3 months postintervention, there was 51\% reduction in CRBSI rate. By reimplementation of the bundles and regular direct feed. back along with the multidisciplinary team approach in tackling CVADs associated complications, it had been revealed by our nursing staffs on increasing compliance with the bundles leading to a significant decrease in CRBSI at 6-month postintervention and occlusion at both 3- and 6- month postintervention. This coincided with the study by Duffy et al. ${ }^{22)}$ and McMullan et al. ${ }^{23)}$ that demonstrated the usefulness of bundles reinforcement on compliance of CVADs care which ultimately resulted in a fall of complication rates.

This study was one of the first studies in Asia in evaluating the effectiveness of care bundles reinforcement with regular feedback on other CVADs complications rather than infection alone. Furthermore, our study also demonstrated the effectiveness of the intervention on a wider range of patients not restricting to critically ill or oncology patients. CRBSI and occlusion rates may vary upon patients' severity and hematologic characteristics. Despite the fact that $80 \%$ of CVADs access was performed in the intensive care unit, only 50\% require emergency access. Some of CVADs access were done in stable patients requiring parenteral nutrition. Patient's severity and hematologic characteristics were similar among each period. Our results agreed with a large metaanalysis by Ista et al. ${ }^{9)}$ that CVADs bundles can reduce the risk of central line-associated infections in pediatric populations (IRR, $0.47-0.58)$.

In terms of dislodgement, we found no statistically significant increase in the incidence during the first 3 months of the intervention. The multidisciplinary team meeting was done and found that most dislodgement occurred in children with neurologic and behavioral problems who were unable to control impulse and behavior. Thus, we executed applications of hand restraints with gloves or pads in these high-risk patients for prevention of auto-removal of the catheters.
There were several limitations to this study. Since this was a single-center study, the results might not be generalizable to other centers with different levels of facilities. Furthermore, due to the small sample size of the population, it revealed a nonsignificant reduction of CRBSI at 3-month postintervention with wide $95 \%$ CI. Moreover, since this study was conducted in only 6-month period postintervention, it might not reveal the true effectiveness of the intervention as well as the sustainability. A long-term, large multicenter study with different levels of facilities should be conducted to further strengthen the effectiveness of reinforcement of care bundles and regular feedback on CVADs com. plications.

In conclusion, reinforcement of CVADs care bundles and direct feedback can significantly decrease CVADs associated complications in terms of infection at 6-month postintervention and occlusion at both 3- and 6-month postintervention. Reinforcement and regular direct feedback might be useful in improving the quality of care in children with CVADs.

\section{Conflicts of interest}

No potential conflict of interest relevant to this article was reported.

\section{Acknowledgments}

The authors would like to show appreciation to all the residents, faculties and nursing staff of the Department of Pediatrics, Faculty of Medicine, Thammasat University Hospital for the strong support and extensive cooperation in making this quality improvement project possible and successful. The authors would also like to thank Assistant Professor Prapasri Gulalert, Department of Epidemiology, Faculty of Medicine, Thammasat University for statistical assistance. The authors would also like to thank Dr. Rapee Opasatian for the support and graphical assistance. 
See the commentary "Catheter care bundle and feedback to prevent central line-associated bloodstream infections in pediatric patients?" via https://doi.org/10.3345/cep.2020.01186.

\section{References}

1. Kleidon T, Illing A, Fogarty G, Edwards R, Tomlinson J, Ullman A. Improving the central venous access devices maintenance process to reduce associated infections in paediatrics: evaluation of a practical, multifaceted quality-improvement initiative. Healthcare Infect 2015;20:46-53.

2. Ullman AJ, Marsh N, Mihala G, Cooke M, Rickard CM. Complications of central venous access devices: a systematic review. Pediatrics 2015;136: e1331-44.

3. Cook LS. Choosing the right intravenous catheter. Home Healthc Nurse 2007;25:523-31.

4. Maki DG, Ringer M. Risk factors for infusion-related phlebitis with small peripheral venous catheters. A randomized controlled trial. Ann Intern Med 1991;114:845-54.

5. Cowl CT, Weinstock JV, Al-Jurf A, Ephgrave K, Murray JA, Dillon K. Complications and cost associated with parenteral nutrition delivered to hospitalized patients through either subclavian or peripherally-inserted central catheters. Clin Nutr 2000;19:237-43.

6. Marschall J, Leone C, Jones M, Nihill D, Fraser VJ, Warren DK. Catheterassociated bloodstream infections in general medical patients outside the intensive care unit: a surveillance study. Infect Control Hosp Epidemiol 2007;28:905-9.

7. Savage T, Hodge DE, Pickard K, Myers P, Powell K, Cayce JM. Sustained reduction and prevention of neonatal and pediatric central line-associated bloodstream infection following a nurse-driven quality improvement initiative in pediatric facility. J Assoc Vasc Access 2018;23:30-41.

8. Son CH, Daniels TL, Eagan JA, Edmond MB, Fishman NO, Fraser TG, et al. Central line-associated bloodstream infection surveillance outside the intensive care unit: a multicenter survey. Infect Control Hosp Epidemiol 2012;33:869-74.

9. Ista E, van der Hoven B, Kornelisse RF, van der Starre C, Vos MC, Boersma $\mathrm{E}$, et al. Effectiveness of insertion and maintenance bundles to prevent central-line-associated bloodstream infections in critically ill patients of all ages: a systematic review and meta-analysis. Lancet Infect Dis 2016;16:724-34.

10. Kim JS, Holtom P, Vigen C. Reduction of catheter-related bloodstream infections through the use of a central venous line bundle: epidemiologic and economic consequences. Am J Infect Control 2011;39:640-6.

11. Schwebel C, Lucet JC, Vesin A, Arrault X, Calvino-Gunther S, Bouadma $\mathrm{L}$, et al. Economic evaluation of chlorhexidine-impregnated sponges for preventing catheter-related infections in critically ill adults in the Dressing Study. Crit Care Med 2012;40:11-7.

12. Srisan P, Juhong S, Kanjanapatanakul W. Central venous catheterization related complications in Pediatric Intensive Care Unit at Queen Sirikit
National Institute of Child Health. J Med Assoc Thai 2014;97 Suppl 6: S83-8.

13. Chuengchitraks S, Sirithangkul S, Staworn D, Laohapand C. Impact of new practice guideline to prevent catheter-related blood stream infection (CRBSI): experience at the Pediatric Intensive Care Unit of Phramongkutklao Hospital. J Med Assoc Thai 2010;93 Suppl 6:S79-83.

14. Holzmann-Pazgal G, Kubanda A, Davis K, Khan AM, Brumley K, Denson SE. Utilizing a line maintenance team to reduce central-line-associated bloodstream infections in a neonatal intensive care unit. J Perinatol 2012; 32:281-6.

15. Rinke ML, Chen AR, Bundy DG, Colantuoni E, Fratino L, Drucis KM, et al. Implementation of a central line maintenance care bundle in hospitalized pediatric oncology patients. Pediatrics 2012;130:e996-1004.

16. Bhutta A, Gilliam C, Honeycutt M, Schexnayder S, Green J, Moss M, et al. Reduction of bloodstream infections associated with catheters in paediatric intensive care unit: stepwise approach. BMJ 2007;334:362-5.

17. Montgomery VL, O'Flynn J, Zink K, Bryant KA, Campbell D. Characteristics of catheter-related bloodstream infections (CRBSI) occurring in a pediatric intensive care unit (PICU) after implementation of an insertion bundle. Paper presented at the 5th World Congress on Pediatric Critical Care; 2007 Jun 24-28; Switzerland, Geneva.

18. Wright MO, Decker SG, Allen-Bridson K, Hebden JN, Leaptrot D. Healthcare-associated infections studies project: an American Journal of Infection Control and National Healthcare Safety Network data quality collaboration: Location mapping. Am J Infect Control 2018;46:577-8.

19. Mermel LA, Allon M, Bouza E, Craven DE, Flynn P, O'Grady NP, et al. Clinical practice guidelines for the diagnosis and management of intravascular catheter-related infection: 2009 Update by the Infectious Diseases Society of America. Clin Infect Dis 2009;49:1-45.

20. Baskin JL, Pui CH, Reiss U, Wilimas JA, Metzger ML, Ribeiro RC, et al. Management of occlusion and thrombosis associated with long-term indwelling central venous catheters. Lancet 2009;374:159-69.

21. O'Grady NP, Alexander M, Burns LA, Dellinger EP, Garland J, Heard $\mathrm{SO}$, et al. Guidelines for the prevention of intravascular catheter-related infections. Clin Infect Dis 2011;52:e162-93.

22. Duffy EA, Rodgers CC, Shever LL, Hockenberry MJ. Implementing a daily maintenance care bundle to prevent central line-associated bloodstream infections in pediatric oncology patients. J Pediatr Oncol Nurs 2015;32:394-400.

23. McMullan C, Propper G, Schuhmacher C, Sokoloff L, Harris D, Murphy P, et al. A multidisciplinary approach to reduce central line-associated bloodstream infections. Jt Comm J Qual Patient Saf 2013;39:61-9.

How to cite this article: Chaiyakulsil C, Pharadornuwat O. Can central venous access device care bundles and regular feedback reduce central line-associated complications in pediatric patients? Clin Exp Pediatr 2021;64:123-9. https://doi.org/ $10.3345 /$ cep. 2020.00143 